\title{
Lexical Bundles: Facilitating University “Talk” in Group Discussions
}

\author{
Chan Swee Heng ${ }^{1}$, Hadi Kashiha ${ }^{1} \&$ Helen Tan ${ }^{1}$ \\ ${ }^{1}$ Department of English, Faculty of Modern Languages and Communication, University Putra Malaysia, \\ Malaysia \\ Correspondence: Hadi Kashiha, Department of English, Faculty of Modern Languages and Communication, \\ University Putra Malaysia (UPM), 43400 UPM Serdang, Selangor, Malaysia. Tel: 60-112-312-4290. E-mail: \\ hadi.kashiha@yahoo.com
}

\author{
Received: November 14, 2013 Accepted: February 18, 2014 Online Published: March 6, 2014 \\ doi:10.5539/elt.v7n4p1 URL: http://dx.doi.org/10.5539/elt.v7n4p1
}

\begin{abstract}
Group discussion forms an integral language experience for most language learners, providing them with an opportunity to express themselves in a naturalistic setting. Multi-word expressions are commonly used and one of them is lexical bundles. Lexical bundles are types of extended collocations that occur more commonly than we expect; they are considered as building blocks in discourse and play a crucial role in creating textual consistency. They contribute to a better understanding of the meaning of particular contexts of language use as well as creating a flow and rhythm in the discourse. This paper investigated the frequency, structures and functions of lexical bundles in a corpus of group discussion of proficient nonnative university undergraduate students, to unravel the application of lexical bundles in managing the talk in group discussion. Results of the analysis showed that lexical bundles accounted for a remarkable proportion of students' lexis in their group discussions; showing a variety of structures and functions that indicate a dexterous yet formulaic automaticity that characterize proficient language use, thus having implications for language learning and teaching.
\end{abstract}

Keywords: group discussion, lexical bundle, multi-word expression, structural and functional analysis

\section{Introduction}

In recent years, using language and its functions to communicate a speaker's opinion has become the focus of many systematic linguistic researches (Bednarek, 2008). In connection with multi-word expressions, the study of formulaic language has a long history in applied linguistics and has attracted many researchers and instructors' attention from the beginning of the last century. Schmitt and Carter (2004) defined formulaic language as combinations of words that perform particular functions and are used automatically by native speakers. The notion of lexical bundle is derived from formulaic patterns of language and has received considerable attention from scholars in the last two decades (Biber, 2006, 2009; Biber \& Barbieri, 2007; Biber \& Conrad, 1999; Biber, Conrad, \& Cortes, 2004; Cortes, 2002, 2004; Hyland, 2008; Wray \& Perkins, 2000). Research in the area of frequently used word sequences follows the works by Altenberg $(1993,1998)$ who established a methodology to recognize frequency-defined recurrent word combinations. The works also categorized the expressions in relation to grammatical and functional analysis.

Biber et al. (1999)) made the first significant step into corpus study in the investigation of these frequent word combinations and suggested two categorizations, functional and structural, to describe the combinations in both written and spoken discourse. They referred to these units as 'lexical bundles' and defined them as "recurrent expressions that usually co-occur in natural language use, regardless of their idiomaticity and their lexical status"(p. 990). Later, Cortes (2004) referred to lexical bundles as extended collocations. Many researchers have stressed the significance of these multi-word expressions in spoken and written discourse. Lexical bundles are "important building blocks in discourse" (Biber \& Barbieri, 2007, p. 270). Hyland (2008) believes that lexical bundles play a crucial role in building coherence in a text and making sense of a particular context. For example, expressions like what I want to say or as far as I know may typically refer to oral participation in group discussion and conversations while on the other hand or in accordance with may be more characteristic of an academic discourse. English language learners have always resorted to using multi-word expressions like lexical bundles in their speech as they are one of the most regular features of fluent linguistic production and account for the characteristic behavior of a mature and fluent speaker. Being able to use such structurally complex sets of words would provide language learners with the needed confidence to engage successfully in an interaction. 
However, in spite of their frequency and importance of use, lexical bundles are not that easy to master as they are both complex and not fixed (Biber \& Conrad, 1999). They are "not idiomatic in meaning and not perceptually salient" (Biber \& Barbieri, 2007, p. 269). Because of this, EFL/ESL learners have always shown difficulty in the effort to activate the use of lexical bundles in their writing or speech. Meanwhile, syllabus designers and language teachers have also realized that such multi-word expressions appear to put language learners in difficulty, since they have no particular sequence, and in most cases, they seem to co-occur in a particular text or speech by chance. Some students may even have difficulty distinguishing whether a particular lexical bundle can exist in a written or oral discourse, as they are not familiar with the forms, grammatical use and meaning of such multi-word combinations. Therefore, language learners require a focused attention on the structural and functional characteristic of lexical bundles, and thus the need for conducting such studies is keenly felt.

Most of the studies in the area of lexical bundles have focused on written discourse with the aim of analyzing different features of lexical bundles in a range of written materials across various disciplines or as a linguistic exploration (Adel \& Erman, 2012; Cortes, 2002, 2004, 2006; Hyland, 2008; Strunkyt \& Jurkūnait, 2008). Among them, Hyland (2008) studied the form, function as well as structure of the most frequent four-word lexical bundles in a 3.5 million word corpus of research articles, doctoral dissertations and Master's theses across four disciplines, namely, electrical engineering and microbiology from the applied and pure sciences, and business studies and applied linguistics from the social sciences. He found that writers of different fields made use of a variety of discipline-specific bundles to "develop their arguments, establish their credibility and persuade their readers" (Hyland, 2008, p. 19). Cortes (2004) explored the distribution of lexical bundles in the university students' writings in biology and history classes. Then, she compared their bundle use with those writings published in history and biology journals and discovered that only 15 bundles (out of 57 target bundles in published journals) were used in the papers written by history students. Adel and Erman (2012) conducted a qualitative and a quantitative study of using lexical bundles in academic writing of advanced Swedish undergraduate university students, and compared it with those of British native speakers in order to come up with possible similarities and differences. They found that native speakers used a wider range of lexical bundles than those of non-native students.

Unlike written discourse, the notion of lexical bundles or any other multi-word expressions in spoken discourse has not received similar treatment from the scholars, but the number of such studies seems to be growing as a result of accessibility to large online spoken corpora. From among the few studies on spoken registers, Nesi and Basturkmen (2009) examined the role of lexical bundles in building cohesion in 160 academic lectures and found that lexical bundles play an important role in cohesion making. Khuwaileh (1999) also addressed the effect of using lexical bundles along with phrases and body language that could enhance Jordanian learners' understanding of university lectures. Most of the studies on lexical bundles in spoken discourse have focused on register other than group discussion, which is the concern of the present research. The studies had focused on academic lectures (Nesi \& Basturkmen, 2009; Khuwaileh, 1999), classroom teaching (Biber, Conrad, \& Cortes, 2004), or conversation (Biber et al., 1999). By reviewing the related literature, it was found that studies on the language use of such formulaic expressions in group discussion are minimal. The lack is even more prominent when it comes to the context of its use among university undergraduate ESL students. Therefore, such a scarcity motivated the researchers to examine the lexical bundle use in group discussion in a university setting to reveal the extent of its use in terms of type, structure and function.

\section{Research Objectives}

The aim of this study is to discover and analyze the most frequent lexical bundles used by ESL university students in group discussions. In addition, the present research aims to reveal the grammatical types as well as discourse functions of the bundles used, so that implications can be drawn for the learning and teaching of lexical bundles. To this end, the following research questions are raised:

1) What are the lexical bundles that are frequently used by university students in group discussions?

2) What are the more prevalent structural and functional types in the bundles used in group discussions?

\section{Method}

\subsection{Corpus and Procedure}

The corpus for this study was derived from 20 group discussion transcripts comprising different topics like how to control the pollution, facilities for university students, factors that cause stress, improving English skills, natural disasters, how to promote thinking skills, and negative effects of the internet. The participants of the group discussions were undergraduate university students from University Putra Malaysia who were enrolled in 
English language proficiency courses.

The collection of the group discussion data that made up the corpus used in this study followed some procedures. First, 90 audio files of group discussions available at University Putra Malaysia language department were reviewed and checked in order to collect information. Only those group discussions that showed a reasonable degree of proficient use of the language were selected, as poor proficiency would not form sample language that is considered as exemplary use, and thus would pose difficulties for structural and functional analysis. Second, only 20 group discussions ranging from 20 to 25 minutes were selected to obtain some control in the length of discourse which could affect the consistency in the identification of lexical bundles. Thus, discussions that were considered too short, with low sound quality or of poor language proficiency were set aside. After selecting the sample group discussions, the researchers transcribed the audio files for later structural and functional analysis of the lexical bundles. To reduce subjectivity, the transcripts were confirmed by another rater, and changes were made where necessary.

This research only focused on three and four-word bundles as previous literature has indicated that three and four-word strings are the most researched size and had been used in many related studies. Moreover, as Cortes (2004) argues, they provide researchers with more obvious varieties of structures and functions. In the procedure of the analysis, this study used the computer program AntConc 3.2 to identify and make a list of the most frequent three and four-word lexical bundles. The target bundles were selected based on the criterion that the identified three or four-word string had to be used in at least $20 \%$ of the transcripts to be called a lexical bundle.

The analytical procedure commenced with the calculation of the frequency of occurrence of the bundles. Three and four-word lexical bundles were then classified according to their structures or grammatical types and functions or meanings, using the structural and functional taxonomies devised by Biber et al. (2004). Structurally, lexical bundles have three major types: 1) verb phrase fragments (is related to the), 2) dependent clause fragments (I need you to), and 3) noun or prepositional phrase fragments (in the case of). Each structural category includes a number of sub-categories which are illustrated in Table 1.

Table 1. Grammatical types of lexical bundles (Biber et al., 2004, p. 381)

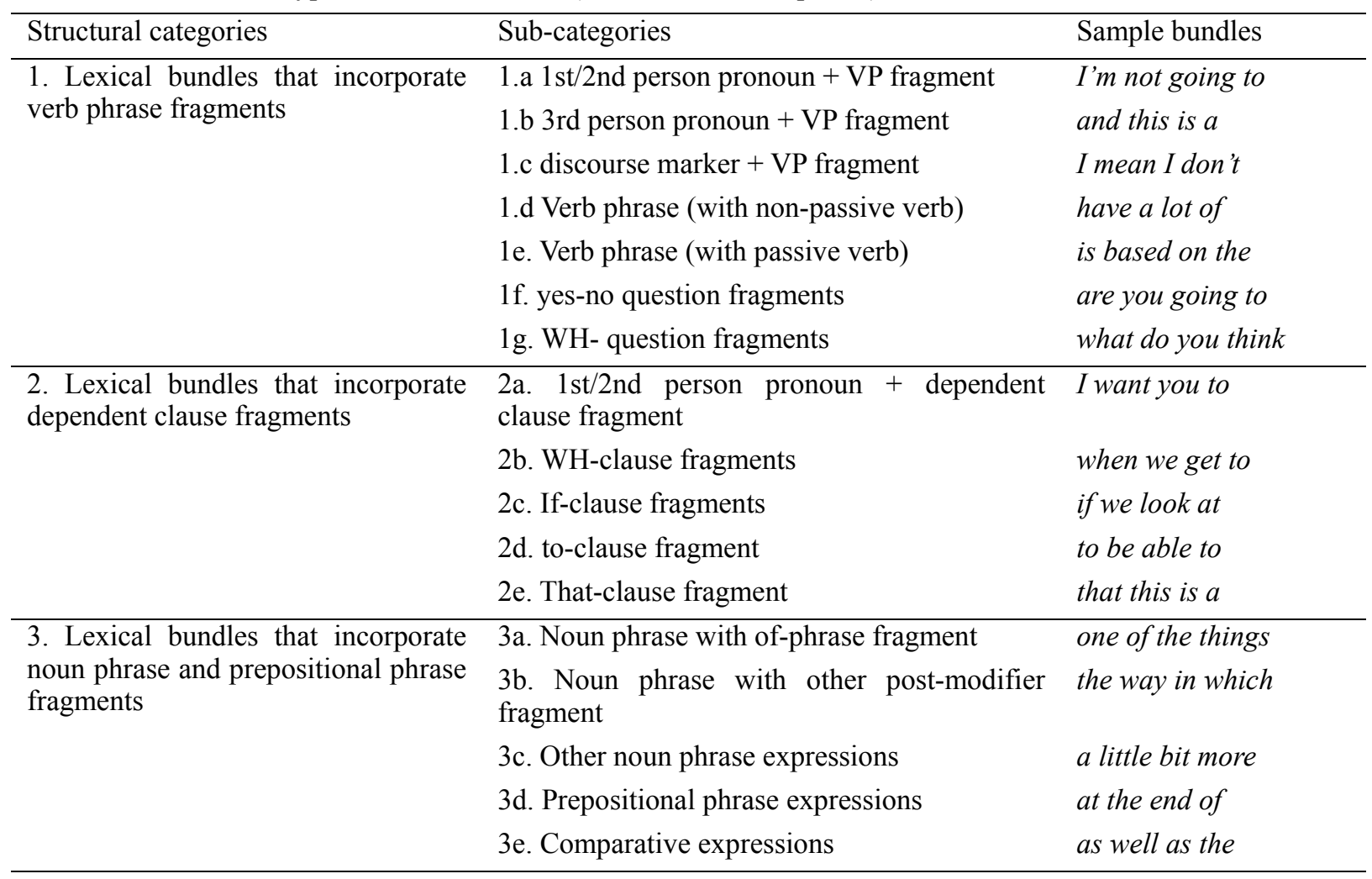

The classification for analyzing the functions or meanings of lexical bundles in this study is also adopted from the framework introduced by Biber et al. (2004). They introduced three main functions for lexical bundles: 
Stance bundles, discourse organizers, and referential bundles. Stance bundles are defined as the "overt expression of an author's or speaker's attitudes, feelings, judgments, or commitment concerning the message" (Biber et al., 2004, p. 386). Discourse organizer bundles try to indicate the general overview of the sentence. Referential bundles single out some important features of an identity to be important in a way. The main functional categories entail a number of sub-functions which provide specific discourse functions, (see Table 2).

Table 2. Functional types of lexical bundles (Biber et al., 2004, pp. 386-388)

\begin{tabular}{lll}
\hline Functional types & Sub-functions & Examples \\
\hline 1. Stance bundles & A. Epistemic stance & the fact that the \\
& B. Attitudinal/modality stance & \\
B1) Desire & I want you to \\
& B2) Obligation/directive & it is important to \\
& B3) Intention/ Prediction & we are going to \\
& B4) Ability & to be able to \\
\hline 2. Discourse organizers & A. Topic introduction & in this chapter we \\
& B. Topic elaboration/clarification & on the other hand \\
& A. Identification/ focus & one of the things \\
& B. Imprecision & or something like that \\
& C. Specification of attributes & \\
C1) Quantity specification & a little bit of \\
\hline C2) Tangible framing & in the form of \\
& C3) Intangible framing & on the basis of \\
D. Time/ Place/ Text reference & \\
& D1) Place reference & in the United States \\
D2) Time reference & at the same time \\
& D3) Text-deixis & as shown in table \\
D4) Multi-functional reference & in the middle of
\end{tabular}

\section{Result and Discussions}

\subsection{Frequency of Lexical Bundles}

Altogether, there were 72 different bundle types found in the 53240 words corpus of group discussions, which comprised 34 three-word, 29 four-word and 9 five-word lexical bundles. Table 3 shows that students were more akin to the use of three and four-word bundles in their discussions, that is, three-word bundles were used 341 times and four-word bundles 328 times, while five-word bundles appeared far less, with only 23 times in the whole corpus. This affirms the justification for the focus on three to four word lexical bundles in the study.

Table 3. Lexical bundles frequency information

\begin{tabular}{lccc}
\hline Lexical bundles & bundle types & Total cases & \% age of total words \\
\hline Three-word & 34 & 341 & 6.43 \\
Four-word & 29 & 328 & 6.18 \\
Five-word & 9 & 23 & 0.43 \\
\hline
\end{tabular}

Table 4 below indicates that the bundle $I$ think that was the most frequently used three-word bundle ( 52 tokens), and appeared in all of the 20 group discussion transcripts. It was used about twice as much as the third placed bundle in my opinion. As can be seen, the top 3 three-word bundles accounted for almost one-third of the whole three-word bundles in the corpus. As for the four-word bundles, the most frequent bundle was I agree with you (64 tokens). The bundle was about four times as frequent as the next placed bundles, my point of view and the 
end of the. On its own, it accounted for almost $19 \%$ of the total four-word bundles in the corpus.

Table 4. Most frequent three and four-word lexical bundles

\begin{tabular}{lccc}
\hline Three-word & Frequency & Four-word & Frequency \\
\hline I think that & 52 & I agree with you & 64 \\
we have to & 39 & my point of view & 17 \\
in my opinion & 26 & the end of the & 16 \\
how about you & 24 & the role of the & 16 \\
in order to & 21 & what do you think & 14 \\
a lot of & 20 & is the way to & 12 \\
you need to & 17 & the best way to & 11 \\
you have to & 16 & is based on the & 10 \\
\hline
\end{tabular}

\subsection{Structural Distribution of Lexical Bundles in Group Discussions}

In addition to the frequency tabulation, analysis of the corpus also showed that students used a variety of structures to form lexical bundles in their discussions. According to the taxonomy used, lexical bundles are either verb phrase, dependent clause, or noun phrase and prepositional phrase. Results of the analysis showed that most of the target bundles fell largely under the phrasal rather than clausal type. These bundles mainly contained either noun, prepositional or verb phrases. Table 5 gives the percentages of the main grammatical structures of the bundles in group discussion. As can be seen, verb phrase along with noun and prepositional phrase were the most commonly used structures, covering almost $94 \%$ of the types. In contrast, dependent clause fragments accounted for only a small proportion of lexical bundles.

Table 5. Structural distribution of target bundles in group discussions (\%)

\begin{tabular}{lcc}
\hline Structural types & No. of bundle types & $\%$ age \\
\cline { 2 - 3 } VP fragments & 32 & 50.8 \\
NP and PP fragments & 27 & 42.8 \\
Dependent clause fragments & 4 & 6.4 \\
\hline Total & & 100 \\
\hline
\end{tabular}

Note: $V P=$ verb phrase; $N P=$ noun phrase; $P P=$ prepositional phrase

As for the verb phrase fragments, results revealed that they were used slightly more than noun and prepositional phrase fragments, with 32 different bundles compared with 27 respectively. Students seemed to rely more on verb phrases in order to express their opinion (I think that the), show their agreement or disagreement (I agree with you), ask for more information or introduce a topic by asking yes/no or Wh-questions (what do you think), and even emphasize the topic by using passive tense (is based on the). Noun and prepositional phrase fragments also accounted for almost $43 \%$ of the total proportion of lexical bundles in the corpus. Noun phrase with of-phrase is the most frequent fragment in this structure, with 30 individual bundles.

In general, it may be claimed that group discussion, as a representative of a form of spoken genre, tended to use the two structures, verb phrase and noun and prepositional phrase equally. This appears to be somewhat in contrast with the earlier studies on spoken registers. For example, Biber et al. (2004) discovered that conversation uses more verb phrases and does not normally tend to use bundles with noun and prepositional phrases, as opposed to academic prose. In our corpus of group discussions, lexical bundles with noun and prepositional phrases accounted for more than $40 \%$ of all bundle types.

\subsection{Functional Distribution of Lexical Bundles in Group Discussions}

The analysis of the functions of the lexical bundles in this study also decided on a slight modification of Biber et al.'s (2004) taxonomy. This modification involved an addition of a new category to facilitate the categorization of the bundles which performed specific functions in group discussion. The main category "discussion-specific 
bundles" was devised based on the logical needs of the register and this mirrored the taxonomy found in several studies under different names such as "special conversational functions" (Biber et al., 2004), "research-oriented topic bundles" (Hyland, 2008), "subject-bound bundles" (Cortes, 2004), and "subject-specific bundles" (Jablonakai, 2010). Biber et al. (2004) introduced the category of "special conversational functions" to refer to those four-word strings that are peculiar to conversation. Similarly, the main category "discussion-specific bundles" in this study was introduced to refer to those bundles which perform specific functions related to group discussion. On the basis of their functions, the main category is sub-divided into three sub-functions. The first sub-function is referred to as greeting and was introduced to refer to those lexical bundles that students used to greet each other at the beginning of their turns in discussions (e.g. Good morning everyone). The second sub-function is referred to as agreement/disagreement, and was used to refer to those bundles which express students' agreement or disagreement as they go into mainstream discussion, such as I agree with you. The last sub-function is labeled politeness and follows Biber et al.'s (2004) taxonomy, which fulfills a need to express gratitude in conversation and group discussion. The detailed explanation of these sub-functions will be illustrated by examples from the corpus in section 4.3.4.

The distribution of the main functional types and their sub-categories, along with the new added category (noted in bold) are presented in Table 6 below. As can be seen, referential bundles reported the highest proportion of use, indicating specific attributes such as quantity, quality, time and place. The second common function is elucidated by the stance bundles, with the students using different verbs to express their degree of certainty or uncertainty. Finally, a few instances of lexical bundles were found to serve discussion-specific and discourse organizers functions.

Table 6. Functional types of lexical bundles in group discussions

\begin{tabular}{|c|c|c|c|}
\hline Functional types & Sub-categories & No. of bundles & Example \\
\hline \multirow[t]{6}{*}{ 1. Stance Bundles } & A. Epistemic stance & 5 & I think that the \\
\hline & B. Attitudinal/modality stance & & \\
\hline & B1)Desire & 2 & I want to know \\
\hline & B2)Obligation/directive & 5 & I need you to \\
\hline & B3)Intention/ Prediction & 3 & we are going to \\
\hline & B4) Ability & 1 & this can be done \\
\hline Sub-total & & 16 & \\
\hline \multirow[t]{2}{*}{ 2. Discourse Organizers } & A. Topic introduction/focus & 4 & to talk about the \\
\hline & B. Topic elaboration/Clarification & 2 & on the other hand \\
\hline Sub-total & & 6 & \\
\hline \multirow{11}{*}{ 3. Referential Expressions } & A. Identification/focus & 10 & is one of the \\
\hline & B. Imprecision & 1 & or something like that \\
\hline & C. Specification of attributes & & \\
\hline & C1) Quantity specification & 9 & a little bit of \\
\hline & $\mathrm{C} 2$ ) Tangible framing attributes & 1 & the size of the \\
\hline & C3) Intangible framing attributes & 4 & in terms of the \\
\hline & D. Time/place/topic Reference & & \\
\hline & D1) Place reference & 1 & in front of you \\
\hline & D2) Time reference & 3 & at the same time \\
\hline & D3)Text-deixis & 5 & as you said earlier \\
\hline & D4) Multi-functional Reference & \# & $\#$ \\
\hline Sub-total & & 34 & \\
\hline \multirow[t]{3}{*}{ 4. Discussion-specific bundles } & A. Agreement/disagreement & 4 & I agree with you \\
\hline & B. Politeness & 1 & thank you very much \\
\hline & C. Greeting & 2 & Good morning to all \\
\hline Sub-total & & 7 & \\
\hline Total & & 63 & \\
\hline
\end{tabular}




\subsubsection{Stance Bundles}

As shown in Table 6, there were 16 instances of stance bundles in the corpus of discussions. Most of them belonged to the attitudinal/modality category which typically involved the use of the personal pronoun ' $I$ '. Obligation/directive expressions were the most common bundles of this type, which were highly employed by the instructors to initiate the discussions and direct the students toward the rules and obligations in participating in the discussions, like in:

E.g. I need you to participate actively in the discussion with your classmates.

Only two of the obligation/directive stance bundles were found to be impersonal (it is important to, it is necessary to), without any personal pronoun:

E.g. So, from this point, I can say that it is important to overcome the negative effects of the internet.

There was only one instance of lexical bundles that expressed ability (this can be done), and three bundles that functioned as intention/prediction ( $I$ am going to, it is going to, they are going to) which were used by the participants to show their intention or predict future events, as in:

E.g. So, the role of the university is ... they are going to provide WIFI service for college students.

Students used desire bundles to express their wishes or make request. All the desire bundles in the corpus were personal expressions:

E.g. I want to point out my opinions that English language skills can be improved by the formal use of English

Most of the personal desire bundles were also used to introduce a new topic such as I would like to; which will be explained in section 4.3.2.

Finally, epistemic stance bundles also accounted for 5 lexical bundles in the corpus, all including personal expressions except for (the fact that the) which as Biber et al. (2004) noted, express the degree of uncertainty. Students used personal epistemic stance bundles to show that they were not completely sure about what they were saying rather than showing a lack of knowledge, as in:

E.g. I don't think that they should worry about how to handle the stress.

\subsubsection{Discourse Organizer Bundles}

Results demonstrated that discourse organizer bundles had two major functions in group discussions, topic introduction/focus and topic elaboration/clarification. Topic introduction/focus bundles were used as a point of departure for the students to initiate their turn in discussions:

E.g. I would like to add to your point that all these accommodations are very important.

Some of these bundles had another function of desire or intention, but their main function was to publicize the topic, as in:

E.g. Let me start first. I want to talk about students' facilities on campus.

Topic elaboration/clarification bundles were mainly used to clarify a piece of information or provide the peers with further explanation, as in:

E.g. In addition to the facilities mentioned, medical universities also provide health services to the students.

\subsubsection{Referential Bundles}

Referential bundles were the most prevalent functional category and accounted for more than half of the bundles in group discussions. These bundles generally functioned as identifying entities or specifying particular attributes of the entities to be important. As shown in Table 6, the most common sub-functions of referential bundles were specification of attributes with 14 instances, identification/focus with 10 counts, and time/place/topic reference with 9 counts. As for the other sub-categories, quantity specification with 9 and text-deixis with 5 types, were reported as the next common sub-functions. The latter was used to refer to those opinions earlier mentioned by other participants in the discussion, as in:

E.g. Well, as you said earlier about the role of the government, I also believe that government plays a major role in blocking some of the websites.

There were only a few bundles referring to time, placed at the end or beginning of the discussion, or to the place of objects in the discussion. No bundle of this nature was found to serve more than one function (multi-functional reference bundles) in the corpus. Some lexical bundles were used to specify measure or quantity in evaluating people or things: 
E.g. Such as Tsunami just happened in Japan, they have lost thousands of people, also they have lost $a$ lot of property like houses ...

The only tangible framing bundle in the group discussion corpus was the size of the, which refers to the size of the room in the example below:

E.g. Yeah, I agree with you. Besides, the size of the rooms is also important as to give the best environment for university students to take rest.

The four examples of intangible framing bundles identified some abstract features of entities and were used to create some reasonable relationships between the students' statements in the discussions, as in the following example:

E.g. In terms of the social effects, I believe natural disaster will have the most effect on economy.

Finally, identification/focus bundles seemed to have several functions in the group discussions. They were used either to start the discussion by uttering the key point (example 1) or to single out something important about the topic (example 2).

1) One of the problems for our students, especially in nowadays economical problem, is the price of food.

2) In my opinion, food is the most important thing.

\subsubsection{Discussion-Specific Bundles}

A new category, discussion-specific bundles, included those lexical bundles that are peculiarly related to group discussion. Based on the functions they serve, it consisted of three sub-categories. The first and most common subcategory, agreement/disagreement referred to students' confirming or opposing another's opinion, especially at the beginning of their turn, as in:

E.g. Yeah, I agree with you that import of the products will be affected as well.

Politeness encompassed those lexical bundles that were mostly used at the end of the discussions as an expression of farewell, either by the participants while leaving the class or by the instructor who thanked students for coming, as in:

E.g. OK, thank you very much. We come to the end of the test. You may leave the room.

Greeting bundles, on the other hand, were exclusively used for welcoming one another at the beginning of the class. In some cases, they also functioned as a topic introducer (as explained in section 4.3.2), as in:

E.g. Good morning everyone. As other candidates said, I also believe that accommodation and library are important, but ...

\subsection{The Relationship between Structural and Functional Analysis}

The findings of the present study are in line with some previous studies claiming that there is a close relationship between the structures of lexical bundles and the functions they serve (Biber et al., 2004; Hyland, 2008). Similar to Biber et al.'s (2004) study on conversation, students in the group discussion corpus tended to use more verb phrase structures. There was a great use of bundles like I would like to or I agree with you to show personal expressions of attitudes and desires. It would also appear that "ownership of ideas" is an important discoursal feature in group discussions, while the use of noun phrase and prepositional phrase structures like in terms of the is indicative of providing audiences with detailed information. These characteristics could well reflect the crucial role of lexical bundles in creating distinct types of discourse and its register (Biber et al., 2004).

\section{Conclusion}

This study aimed to identify and analyze the structural and functional characteristics of lexical bundles in group discussions carried out by proficient ESL university students. On the whole, it was seen that lexical bundles were frequently used in the students' discussions. Given the corpus, it would lend itself to be used in overt instruction of such multi-word combinations that would help the less proficient ESL students to increase the effectiveness of speech training for the purpose of engaging in group discussion. In addition, lexical bundles could be more firmly grounded as a syllabus item in course design and in materials to cater to the needs of ESL/EFL learners. Structurally, the analysis revealed that most lexical bundles used in group discussions were phrasal, including verb-phrase, noun phrase and prepositional phrase fragments, suggesting that such structures should be given more highlight by the instructors while teaching. Regarding the functions that lexical bundles serve, the findings showed that proficient students had automatically and unconsciously applied certain bundles to convey specific discourse functions in their discussions, for example to show ownership of ideas, elaborate on a topic or 
negotiate directions in the development of the discourse. They also used some bundles salient to group discussion itself, such as agreeing or disagreeing, which are crucial for such discursive engagement. This nature of lexical bundles along with the use of a large number of bundle types in the register of group discussion makes it essential that students raise their awareness towards the importance of learning different types of multi-word combinations.

Further research could focus on how lexical bundles are manifested and applied in other university registers such as those found in oral presentation or even in the language of debate as they are instances of language use that often characterize language engagement in a university environment. In this manner, different 'real live' corpora can be captured to illustrate lexical bundles specific to different genres to give significance and recognition to these registers in learning and teaching. In addition, the findings of the present study could be compared to the written activities of students such as essay writing to reveal differences in speech and writing which have distinctive structural and functional attributes of the multi-word expressions used for the stated purpose. Such comparative investigations may offer a more comprehensive picture of formulaic expressions and lexical bundles used in university context for language teachers, material designers, and ultimately the most affected, language learners.

\section{References}

Adel, A., \& Erman, B. (2012). Recurrent word combinations in academic writing by native and non-native speakers of English: A lexical bundles approach. English for Specific Purposes, 31(2), 81-92.

Altenberg, B. (1993). Recurrent word combinations in spoken English. In J. D. Arcy (Ed.), Proceedings of the fifth Nordic Association for English Studies Conference (pp. 17-27). Reykjavik: University of Iceland.

Altenberg, B. (1998). On the phraseology of spoken English: The evidence of recurrent word combinations. In A. Cowie (Ed.), Phraseology: Theory, analysis and applications (pp. 101-122). Oxford: OUP.

Bednarek, M. (2008). An increasingly familiar tragedy: Evaluative collocation and conflation. In M. Bednarek (Ed.), Evaluation in text types. Special issue of Functions of Language, 15(1), 7-34. John Benjamins Publishing Company.

Biber, D. (2006). University language: A corpus-based study of spoken and written registers. Amsterdam: Benjamin.

Biber, D. (2009). A corpus-driven approach to formulaic language in English. International Journal of Corpus Linguistics, 14(3), 275-311.

Biber, D., \& Barbieri, F. (2007). Lexical bundles in university spoken and written registers. English for Specific Purposes, 26(3), 263-286.

Biber, D., \& Conrad, S. (1999). Lexical bundles in conversation and academic prose. In H. Hasselgard, \& S. Oksefjell (Eds.), Out of corpora (pp. 181-190). Amsterdam: Rodopi.

Biber, D., Conrad, S., \& Cortes, V. (2004). If you look at ...: Lexical bundles in university teaching and textbooks. Applied Linguistics, 25, 371-405.

Biber, D., Johansson, S., Leech, G., Conrad, S., \& Finegan, E. (1999). Longman grammar of spoken and written English. London: Longman.

Cortes, V. (2002). Lexical bundles in published and student academic writing in history and biology (Unpublished Doctoral dissertation, Northern Arizona University).

Cortes, V. (2004). Lexical bundles in published and student disciplinary writing: Examples from history and biology. English for Specific Purposes, 23, 397-423.

Cortes, V. (2006). Teaching lexical bundles in the disciplines: An example from a writing intensive history class. Linguistics and Education, 17(4), 391-406.

Hyland, K. (2008). As can be seen: Lexical bundles and disciplinary variation. English for Specific Purposes, 27, 4-21.

Jablonkai, R. (2010). English in the context of European integration: A corpus-driven analysis of lexical bundles in English EU documents. English for Specific Purposes, 29(4), 253-267.

Khuwaileh, A. A. (1999). The role of chunks, phrases and body language in understanding co-ordinated academic lectures. English for Applied Studies (pp. 249-260). Jordan University of Science and Technology.

Nesi, H., \& Basturkmen, H. (2009). Lexical bundles and discourse signalling in academic lectures. Lexical 
Cohesion and Corpus Linguistics, 17, 23.

Schmitt, N., \& Carter, R. (2004). Formulaic sequences in action: An introduction. In N. Schmitt (Ed.), Formulaic sequences: Acquisition, processing, and use (pp. 1-22). Philadelphia: John Benjamins.

Strunkyt, G., \& Jurkūnait, E. (2008). Written academic discourse: Lexical bundles in humanities and natural sciences (Unpublished BA thesis. Vilnius: University Faculty of Philology, Department of English Philology).

Wray, A., \& Perkins, M. (2000). The functions of formulaic language. Language and Communication, 20, 1-28.

\section{Copyrights}

Copyright for this article is retained by the author(s), with first publication rights granted to the journal.

This is an open-access article distributed under the terms and conditions of the Creative Commons Attribution license (http://creativecommons.org/licenses/by/3.0/). 